\title{
How effective and safe is medical cannabis as a treatment of mental disorders? A systematic review
}

\author{
Eva Hoch $^{1} \cdot$ Dominik Niemann ${ }^{1} \cdot$ Rupert von Keller $^{1} \cdot$ Miriam Schneider $^{2} \cdot$ Chris M. Friemel $^{1} \cdot$ Ulrich W. Preuss ${ }^{3}$. \\ Alkomiet Hasan ${ }^{1}$. Oliver Pogarell ${ }^{1}$
}

Received: 14 September 2018 / Accepted: 3 January 2019 / Published online: 31 January 2019

(c) The Author(s) 2019, corrected publication 2019

\begin{abstract}
We conducted a review of systematic reviews (SRs) and randomized-controlled trials (RCTs) to analyze efficacy and safety of cannabis-based medication in patients with mental disorders. Five data bases were systematically searched (2006-August 2018); 4 SRs (of 11 RCTs) and 14 RCTs (1629 participants) were included. Diagnoses were: dementia, cannabis and opioid dependence, psychoses/schizophrenia, general social anxiety, posttraumatic stress disorder, anorexia nervosa, attention-deficit hyperactivity disorder, and Tourette`s disorder. Outcome variables were too heterogeneous to conduct a meta-analysis. A narrative synthesis method was applied. The study quality was assessed using the risk-of-bias tool and SIGN-checklists. THC- and CBD-based medicines, given as adjunct to pharmaco- and psychotherapy, were associated with improvements of several symptoms of mental disorders, but not with remission. Side effects occurred, but severe adverse effects were mentioned in single cases only. In order to provide reliable treatment recommendations, more and larger RCTs with follow-up assessments, consistent outcome measures and active comparisons are needed.
\end{abstract}

Keywords Mental disorders $\cdot$ Cannabis $\cdot$ Cannabinoids $\cdot$ THC $\cdot$ CBD $\cdot$ Medical cannabis $\cdot$ Treatment

\section{Introduction}

Mental disorders are among the leading causes of health impairments $[25,77,89,91]$ involving significant changes in thinking, perception, emotion, behavior and relationships [4]. They are considered as strongly restricting conditions, leading to distress for both patients and their families [19]. The etiology of mental disorders is complex, including genetic, neurobiological, psychological and environmental factors across the lifespan [64].

Recently, the efficacy and safety of cannabis-based medicines for treatment or alleviation of mental disorders has

Eva Hoch

Eva.Hoch@med.uni-muenchen.de

1 Cannabinoid Research and Treatment Group, Department of Psychiatry and Psychotherapy, University Hospital, LMU Munich, Nußbaumstr. 7, 80336 Munich, Germany

2 APOPO, University of Agriculture, Martin-Luther-University, Morogoro, Tanzania

3 Vitos Hospital Psychiatry and Psychotherapy, Department of Psychiatry, Psychotherapy and Psychosomatics, Martin-Luther-University, Halle-Wittenberg, Germany been tested more systematically. Cannabis is a flowering plant with different species producing major compounds such as the psychoactive component delta-9-tetrahydrocannabinol (THC) and cannabidiol (CBD), which have partially antagonistic effects $[9,52,69]$. THC can change mood, sensation, perception, tension, appetite, and pain; CBD has shown anxiolytic, antipsychotic, neuroprotective, anti-inflammatory and antiemetic properties [8, 34, 54, 57]. The medical use of herbal cannabinoids declined early in the twentieth century due to emerging evidence of their health risks and addictive potential [22]. However, growing interest in the substance as medicine was renewed in the 1990s with the discovery of cannabinoid receptors 1 and 2 (CB1 and $\mathrm{CB} 2$, respectively), endogenous ligands (endocannabinoids; $N$-arachidonoylethanolamine (anandamide/AEA) and 2-arachidonoylglycerol (2-AG)), and enzymes as part of an endogenous cannabinoid system $(\mathrm{eCB})$ in the brain $[49,53]$. The $\mathrm{eCB}$ is regarded as a fundamental regulatory apparatus connected with nearly every physiological and pathological aspects of mammalian biology [21]. The correct interplay between all these endocannabinoid system elements plays an important role in central nervous system (CNS) development, synaptic plasticity, motor control, memory, cognition, 
stress, emotional responses, reward and motivated behavior, appetite, pain, development and homeostasis $[58,68$, 72]. Outside the brain, the eCB system is one of the crucial modulators of the autonomic nervous system, the immune system, the endocrine network, the gastrointestinal tract, the reproductive system, and in microcirculation [20]. Endocannabinoids are one of the most important systems controlling both excitatory and inhibitory neurotransmission, as well as neuroplasticity [72]. They serve as retrograde signaling messengers in GABAergic and glutamatergic synapses, as well as modulators of postsynaptic transmission, interacting with other neurotransmitters, including dopamine. Endocannabinoids also participate in the modulation of the hypothalamic-pituitary-adrenal (HPA) axis and regulation of stress $[30,75]$. Preclinical and clinical data support the involvement of the eCB in the etiopathogenesis of mental disorders $[24,35,44,73]$. Especially the CB1 receptor, which is the most abundant and widespread receptor throughout the mammalian brain, has become a target of interest [23, 38]. Reported findings from human brain studies are controversial [67] since different alterations in gene and/or protein expression of CB1 receptors have been shown to depend on the technical approach used or the brain region studied [35]. Although the picture is complex and not fully understood, the neuromodulatory function of the eCB System could be an interesting target for pharmacotherapeutic interventions in mental disorders $[24,26,50,57,67,70]$. The synthesis of cannabinoid receptor agonists and antagonists, anandamide uptake blockers and inhibitors of endocannabinoid anandamide degradation has further opened up new treatment strategies [26, 72].

On the other hand, cannabis is the most frequently used illegal substance worldwide [92] and scientific evidence indicates that chronic exposure to cannabinoids may increase mental health risks, such as impaired cognition, depression, anxiety, psychoses and cannabis dependence in vulnerable persons $[27,32,63,86]$. On a neurophysiological basis, chronic use of cannabinoids can impair CB1R function; create a loss of eCB-mediated synaptic plasticity in neural circuits, and cause addiction and negative affective states [68]. Based on these cannabis-related controversies, this paper is aimed at systematically screening the scientific literature of randomized-controlled trials (published between 2006 and 2018) to assess the efficacy and safety of cannabis-based medicines as a treatment of mental disorders.

\section{Methods}

This systematic review followed guidance published by the Centre for Reviews and Dissemination and the Cochrane Collaboration [29]. The study protocol is registered with the Centre for Reviews and Dissemination at the University of
York (UK): http://www.crd.york.ac.uk/prospero/DisplayPDF .php?ID=CRD42016053592. This work is part of a large cannabis expertise on potential and risks of cannabinoids [31] commissioned by the German Ministry of Health.

\section{Eligibility criteria}

We searched for systematic reviews (SR) and randomizedcontrolled trials (RCTs) testing the efficacy and safety of medical cannabis (with or without additional medication and psychotherapy) for the treatment of mental disorders. Studies published in English or German language in the past decade were considered.

\section{Information sources}

The data bases PsycINFO, Medline, PubMed, Embase, and the Cochrane Library were used. Hand searches were conducted, researchers in this field were contacted. Reference lists of included studies were screened. Search results and full-text articles were independently assessed by 2 reviewers; disagreements were resolved by consensus or referral to a third reviewer.

\section{Search}

Based on the clinical research questions, we developed three detailed search strategies for identifying studies. Medical subject headings ("mesh-Terms"; U.S. National Library of Medicine 2017 https://www.nlm.nih.gov/mesh/) were used to build and pilot test search strings, which were finally adapted to the different data bases (Table 1).

\section{Study selection}

The search process was documented in a priori defined research protocols. The study selection process (i.e., screening, eligibility, inclusion in review) was documented in PRISMA flow-charts [56] (Figs. 1, 2, 3). References are archived in EndNoteTM (EndNote X8, Clarivate Analytics).

\section{Data collection process and data items}

Titles and abstracts of studies retrieved using the search strategies were screened independently by two researchers to identify studies which potentially meet the inclusion criteria. The full text of these potentially eligible studies was assessed for eligibility. A standardized form was used to extract data from the included studies for assessment of study quality and evidence synthesis according to the PICO scheme (i.e., baseline characteristics of patients, interventions, comparisons and outcomes). Whereever 
Fig. 1 Literature search of systematic reviews $(\mathrm{SR})$ (\#Search 1)

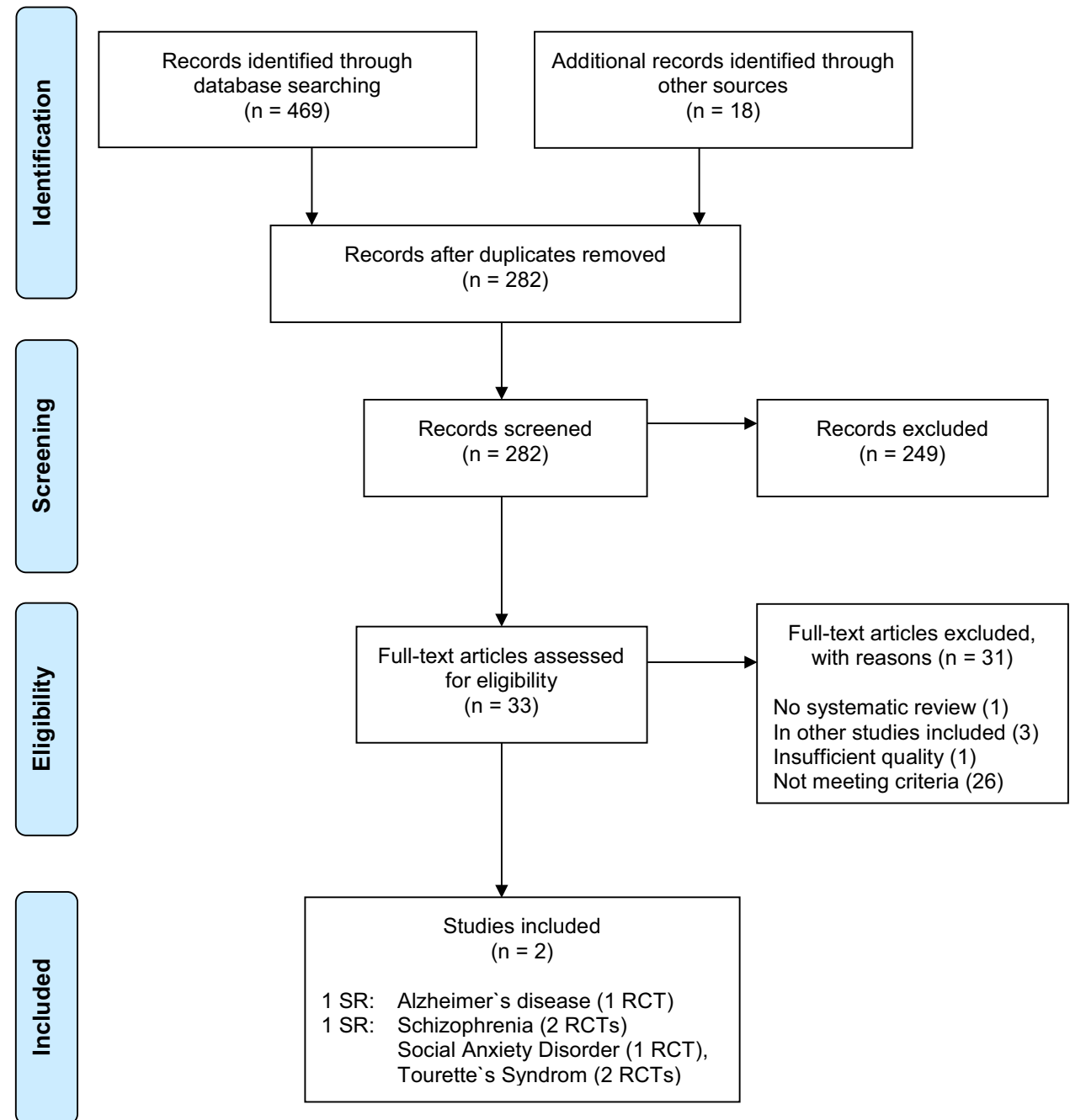

possible, the journal article was used as the primary publication because it had been peer reviewed.

\section{Participants}

Studies were included if they reported diagnostic criteria of mental disorders $[3,4,93]$.

\section{Interventions}

Experimental condition: CB1 receptor agonists (dronabinol, nabilone, nabiximols or THC), CB1 receptor antagonists/inverse agonists (rimonabant, drinabant), cannabinoid modulators (cannabidiol) or any other cannabinoid.

Control condition: placebo and/or other medication and/ or psychotherapy and/or any other intervention different from the experimental condition.

\section{Outcome measures}

Primary outcome was the efficacy of medical cannabinoids for the treatment of any mental disorder. Secondary outcomes were tolerability and safety of medical cannabinoids.

\section{Risk-of-bias assessment and level of evidence}

Qualitative ratings of the selected studies were conducted by using standardized protocols and tools. Systematic reviews were assessed with the Cochrane risk-of-bias tool (http:// www.riskofbias.info/). RCTs were assessed for methodological quality using the SIGN-checklist [76]. Data extraction and risk-of-bias assessment were performed independently by 2 reviewers; disagreements were resolved by a third reviewer. Each study received a level of evidence, based on study type and quality [65]. All documents are available upon request. 


\section{Synthesis of results}

This systematic review applies a qualitative data synthesis approach. Due to high heterogeneity of primary outcome measures in the identified studies, no aggregated data analysis was possible. The study results were interpreted with respect to their sample size, level of evidence, risk of bias and level of heterogeneity/homogeneity.

\section{Results}

\section{Study selection}

The three searches resulted in 1031 screened records. 4 systematic reviews (of $11 \mathrm{RCTs}$ ) and 14 additional RCTs were included (PRISMA flow-charts, Figs. 1, 2, 3). The total number of study participants covered in this review is 1629 . A reference list of excluded studies is available on request.

\section{Participants}

Randomized-controlled trials assessed the following fully diagnosed mental disorders: Alzheimer`s disorder/dementia (4 RCTs), substance use disorders [opioid dependence (2 RCTs); cannabis use disorder (5 RCTs)], psychoses/ schizophrenia (8 RCTs), generalized social phobia (1 RCT), posttraumatic stress disorder (1 RCT), anorexia nervosa (1 RCT), Tourette`s disorder (2 RCTs), attention-deficit hyperactivity disorder (1 RCT).

\section{Types of interventions and comparisons}

The RCTs tested CB1 receptor agonists [dronabinol (6 RCTs), nabiximols (4 RCTs), THC (5 RCTs), nabilone (1 RCTs), CB1 receptor antagonists/inverse agonists [rimonabant (2 RCTs), drinabant (1 RCTs)] or cannabinoid modulators [cannabidiol (CBD) (6 RCTs)]. In many studies cannabis-based medicines were given as add-on to standard medication and psychotherapy.
Fig. 2 Updated search of systematic reviews (SR) and randomized-controlled trials (RCT) (\#Search 2)

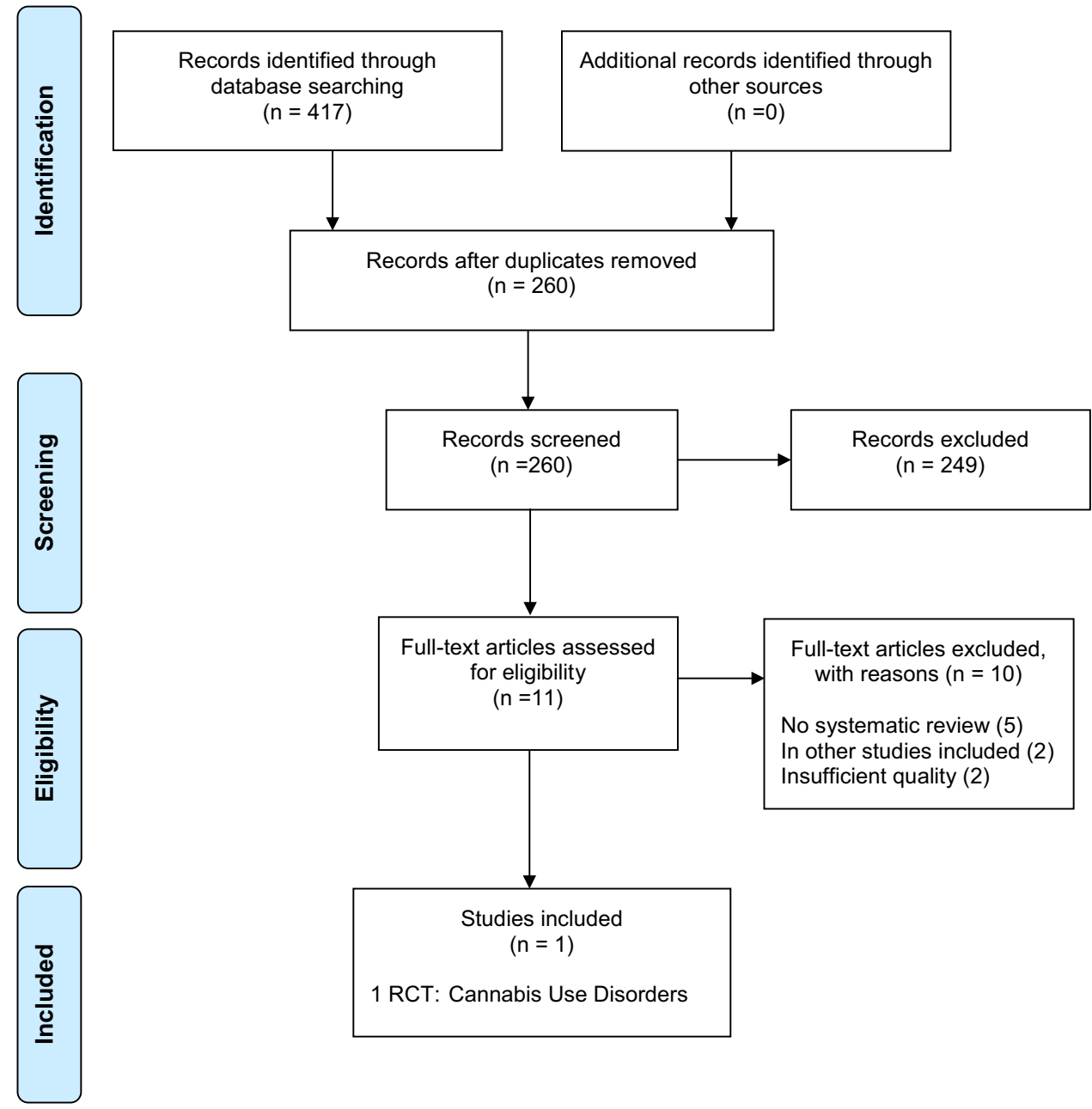


Fig. 3 De novo research of systematic reviews (SRs) and randomized-controlled trials (RCTs)

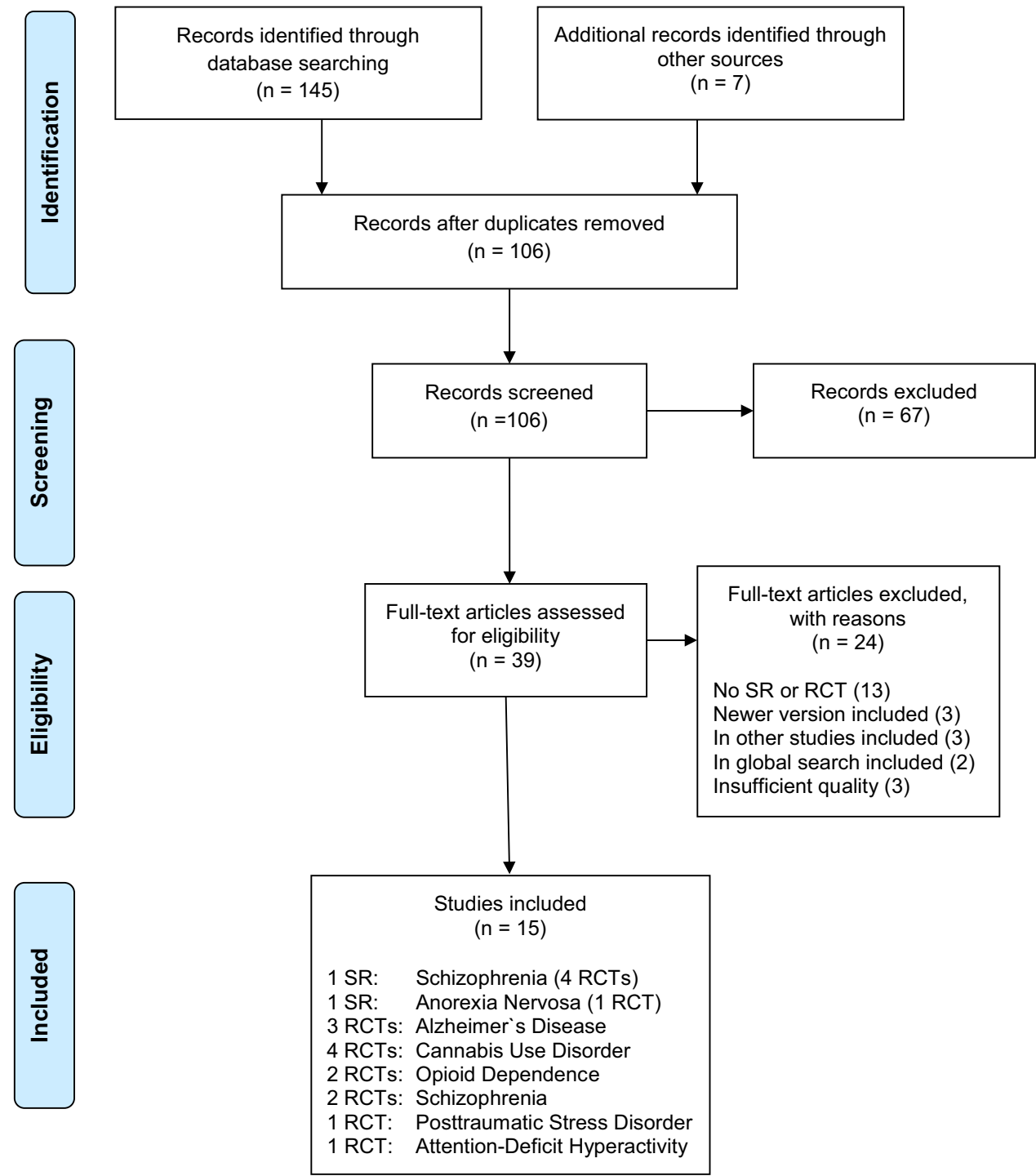

Table 1 Search process, medical subject headings (MeSH)

\begin{tabular}{ll}
\hline Search process & MeSH-terms and search setting \\
\hline Search 1 (2006-2016) & Cannabis OR cannabinoid* OR hemp OR hanf (ti, ab) OR 2) Mariuana OR Marihuana OR Marijuana (ti, ab) \\
Search 2 (2014-2016) & Medical marihuana OR medical marijuana OR medical mariuana OR medical cannabis OR pharmaceutical \\
marihuana OR pharmaceutical marijuana OR pharmaceutical mariuana OR pharmaceutical cannabis (ti, \\
ab) \\
Medical Marijuana OR Cannabinoids OR Cannabinol OR Cannabidiol OR Dronabinol (all fields), (2) \\
Mental Disorders OR Psychotic Disorders OR Schizophrenia OR Depression OR Depressive Disorder OR \\
Dysthymic Disorder OR Bipolar Disorder OR Anxiety Disorders OR Stress Disorders OR Post-Traumatic \\
OR Obsessive-Compulsive Disorder OR Tourette Syndrome OR Sleep Wake Disorders OR Alzheimer \\
Disease OR Anorexia Nervosa OR Substance-Related Disorders (all fields) (3) 1 AND 2 (4) Limit 3 to \\
((human AND (meta-analysis or "systematic review")) OR (human and randomized controlled trial)) AND \\
(English or German)
\end{tabular}

\section{Results of individual studies}

Dementia (FO ICD-10) 1 SR [59] of 1 RCT and 3 additional RCTs were identified [1,82-85]. Volicer et al. [85] found positive effects on mean weight gain in both groups (dronabinol-placebo group by $3.95 \mathrm{~kg}$, placebo-dronabinol group: by $3.13 \mathrm{~kg}$ ) with a pronounced effect of dronabinol compared to placebo $(p=0.017)$ (Table 2$)$. A reduction in 


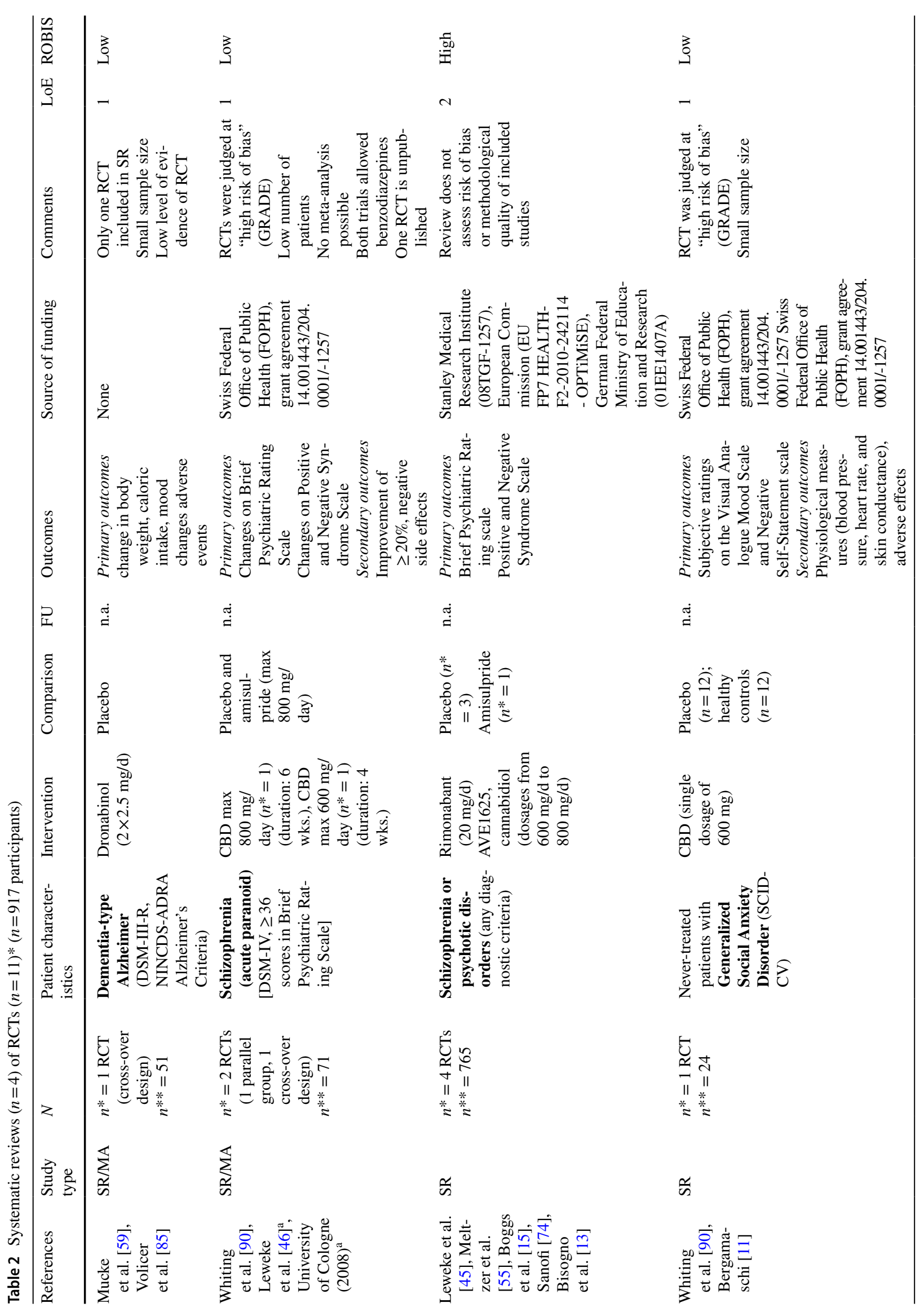




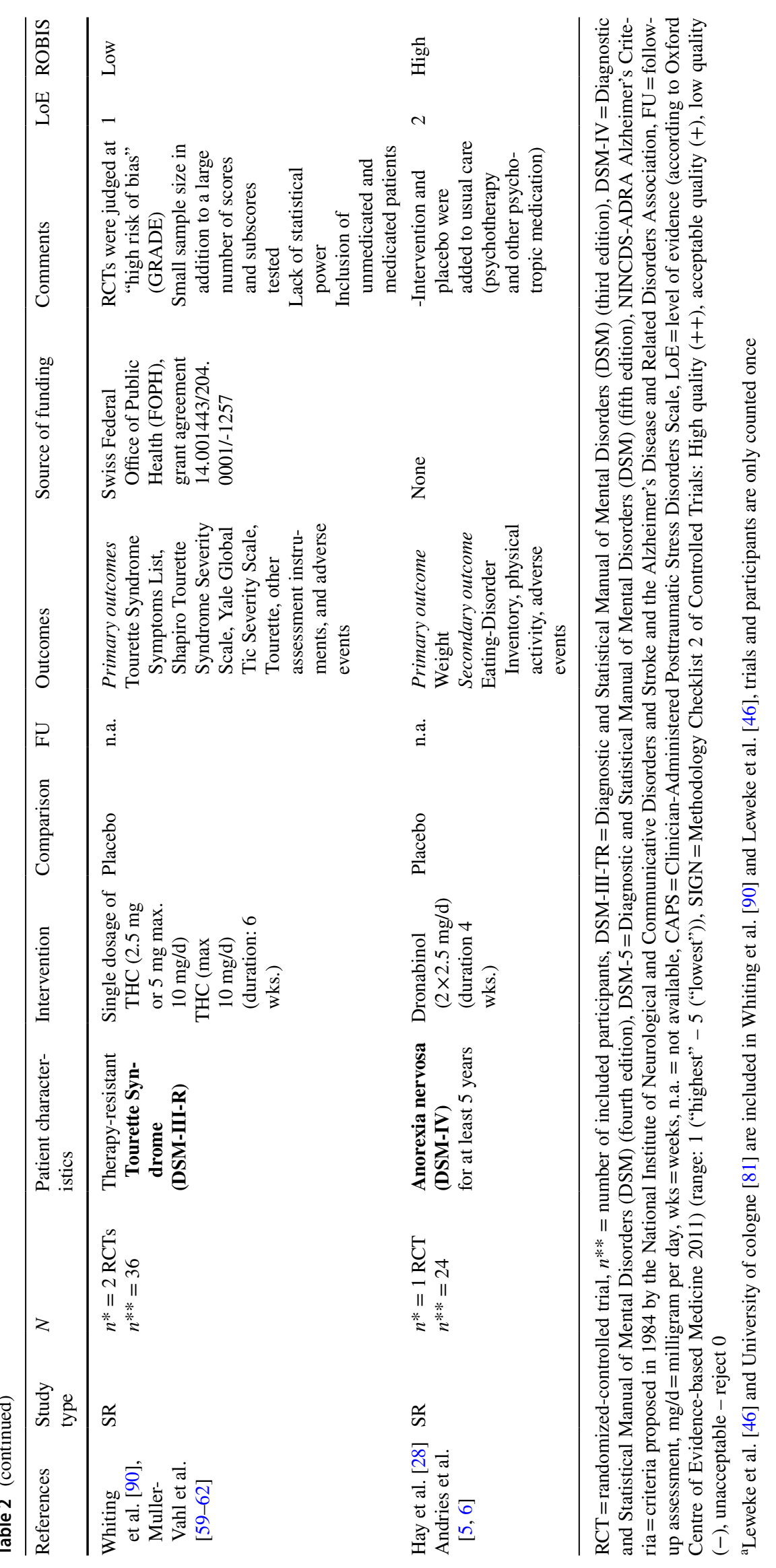


negative affect (anger, anxiety and sadness) was detected during the treatment with dronabinol, which persisted during the episode following the treatment with dronabinol (ANOVA: $\left.\mathrm{F}_{\text {(order } \times \text { treatment) }}=2.78, d f=1,143, p=0,12\right)$. No effects were found for caloric intake. Three patients dropped out of the study [adverse effects $(n=1)$, severe infections $(n=2)$, myocardial infarction during the placebo phase $(n=1)$ ]. In a multi-centered RCT (Table 3$)$ van den Elsen et al. [82] reported that THC did not reduce neuropsychiatric symptoms compared to placebo (block 1-3: $1.8,97.5 \% \mathrm{CI}$ -2.1 to 5.8 ; block $4-6$ : $-2.8,97.5 \% \mathrm{CI}-7.4$ to 1.8 ). Psychiatric symptoms, agitated behavior and caregiver burden increased in both study arms during the 12 weeks trial. THC was well tolerated, as assessed by adverse event monitoring, vital signs and mobility. The incidence of adverse events was similar between treatment groups. Four non-related serious adverse events occurred. In a sample of ten patients, Ahmed et al. [1] reported that THC was rapidly absorbed and had dose-linear pharmacokinetics with considerable variation. Pharmacodynamic effects, including adverse events, were minor. Another RCT with cross-over design [84] tested the efficacy and safety of low-dose oral THC $(3 \times 1-5 \mathrm{mg} /$ day, 3 weeks.) or placebo. Neuropsychiatric symptoms were reduced during both treatment conditions, with no difference between THC and placebo (mean difference NPI total $_{\text {: }}$ 3.2, 95\% CI 23.6-10.0). No changes in scores for agitation, quality of life, or activities of daily living were found. The number of patients experiencing mild or moderate adverse events was similar (THC: $n=16$, placebo: $n=14 ; p=0.36$ ). No effects on vital signs, weight, or episodic memory were observed. In all trials, patients could continue their standard medication. In summary, the studies provide a heterogeneous picture: superior effects (weight gain and reduction in negative affect) of THC (given in addition to standard treatment and compared to placebo) were only found in one out of three trials. Adverse effects occurred in all conditions.

Opioid dependence (F11.20 ICD-10) Severity of withdrawal, retention in treatment or safety were assessed in 2 RCTs (3 reports, 70 patients) [12, 37, 48] (Table 3). The first intervention [12] was dronabinol (titrated to $30 \mathrm{mg} /$ day, 3 weeks) $(n=40)$ compared to placebo $(n=20)$. Patients were stabilized with buprenorphine $(2 \times 4 \mathrm{mg} /$ day) (day 2 ) and received naltrexone from day 5 onwards. The study revealed a significant initial reduction in the severity of the opioid withdrawal during the initial 8-day detoxification phase for dronabinol (up to $30 \mathrm{mg} /$ day) compared to placebo $(p=0.006)$. No significant difference was found in retention between the groups (35\% retained in either group). The rate of successful induction onto XR-naltrexone did not differ between dronabinol (66\%) and placebo (55\%) groups $\left(\chi^{2}=1.46, p=0.23\right)$. A high number of AEs (96\% vs. $\left.91 \%\right)$ was reported. They were considered to be consistent with symptoms of naltrexone-related protracted withdrawal. Jicha et al. [37] and Lofwall et al. [48] tested the safety of dronabinol with $n=12$ adults physically dependent on short-acting opioids. Participants were maintained on oral $30 \mathrm{mg}$ oxycodone. The study showed that a higher dosage of dronabinol ( $40 \mathrm{mg} /$ day) produced sustained sinus tachycardia accompanied by anxiety and panic necessitating dose reduction to $30 \mathrm{mg}$. Compared to placebo, 20 and $30 \mathrm{mg}$ dronabinol produced significant increases in heart rate beginning $1 \mathrm{~h}$ after drug administration which lasted approximately $2 \mathrm{~h}$ $(p<0.05)$. Dronabinol 5 and $10 \mathrm{mg}$ produced placebo-like effects. Altogether, the evidence for the usefulness of dronabinol as adjunct medication in the detoxification of opioiddependent patients is still very small. Only one study shows a reduction in the severity of the opioid withdrawal in the initial detoxification phase. The number of reported adverse events was high in one study (naltrexone-related protracted withdrawal) while safety concerns were given in the second study for dronabinol at $20 \mathrm{mg}$ and higher given in combination with oral oxycodone.

Cannabis dependence (F12.2 ICD-10) Craving, withdrawal and abstinence from cannabis were assessed in 5 RCTs (319 participants) in patients with cannabis dependence [2, 42, 43, 79, 80]. Trigo et al. [80] (Table 3) added nabiximols or placebo to a manualized motivational enhancement therapy and cognitive behavioral therapy. Rates of adverse events did not differ between treatment arms $\left(F_{1,39}=0.205, \mathrm{~ns}\right)$. There was no significant change in abstinence rates at trial end. Cannabis use decreased in either group, without significant differences between treatment conditions $(p=0.179)$. Nabiximols reduced cannabis craving, but no significant differences between groups were observed on withdrawal scores. No serious adverse events were reported. In a previous multi-centered RCT with cross-over design, Trigo et al. [79] tested the effects of nabiximols on both craving and withdrawal symptoms among $n=9 / 16$ non-treatment seeking cannabis-dependent adults. High fixed doses of nabiximols were well tolerated and, compared to placebo, significantly reduced symptoms of cannabis withdrawal during abstinence, but not craving. Self-titrated doses were lower and showed limited efficacy compared to high fixed doses. Participants reported a significantly lower "high" following nabiximols or placebo as compared to treatment as usual conditions. Nausea, diarrhea and sleep disorders were reported, but no serious AEs. Levin et al. [43] assessed abstinence ( $=21$ consecutive days), withdrawal, craving, and adverse events. The intervention was dronabinol (self-titrated up to $3 \times 20 \mathrm{mg} /$ day), lofexidine (self-titrated up to $3 \times 0.6 \mathrm{mg} /$ day) or placebo. In both conditions, patients received cannabis-specific manualized behavioral therapy. The trial found no treatment effect in achieving abstinence. Drop-out rates were high (48\% vs. $42 \%$ ). More AEs were found in the dronabinol group (e.g., dry mouth, intoxication, and hypotension), serious AEs (2 


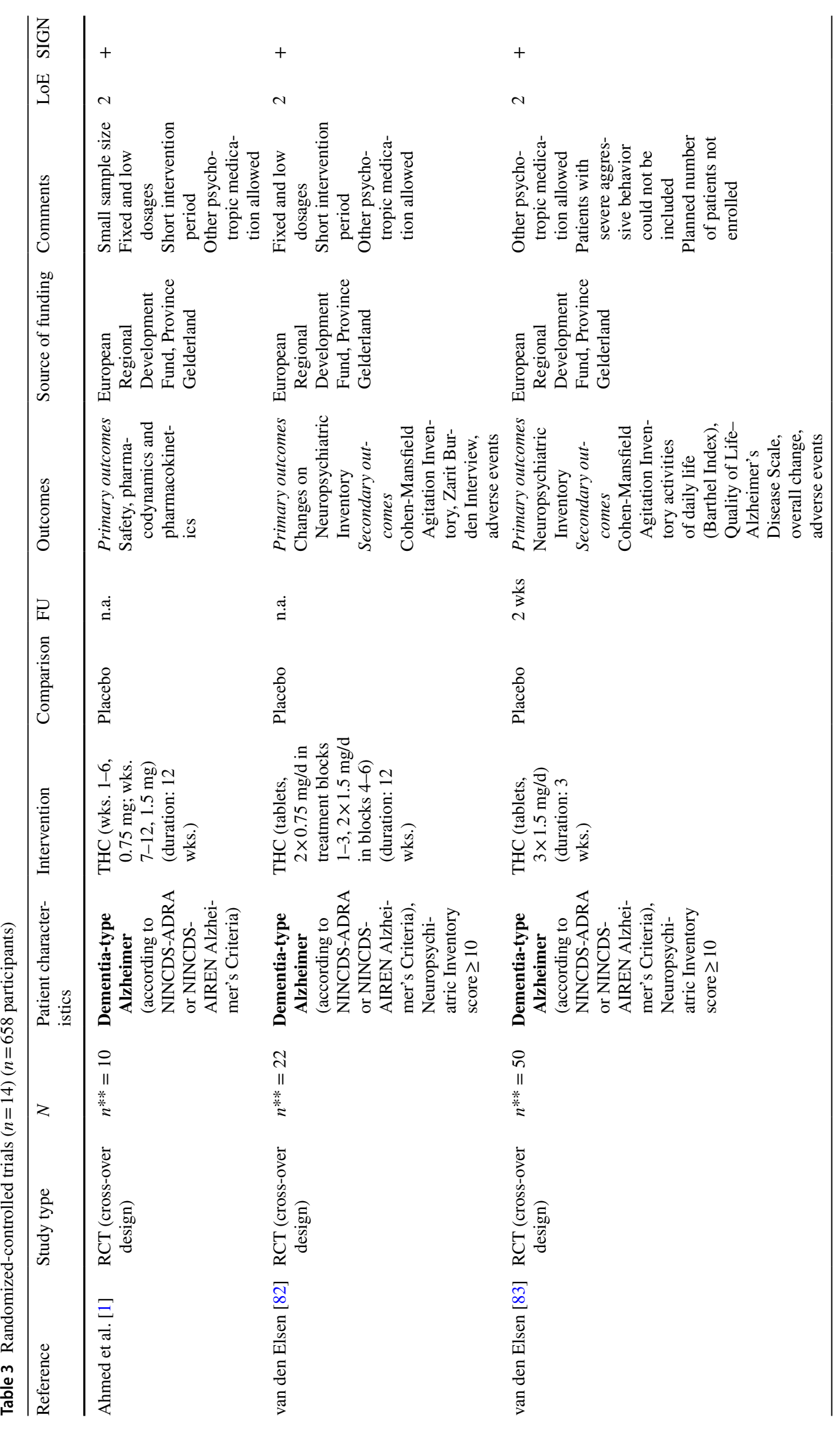




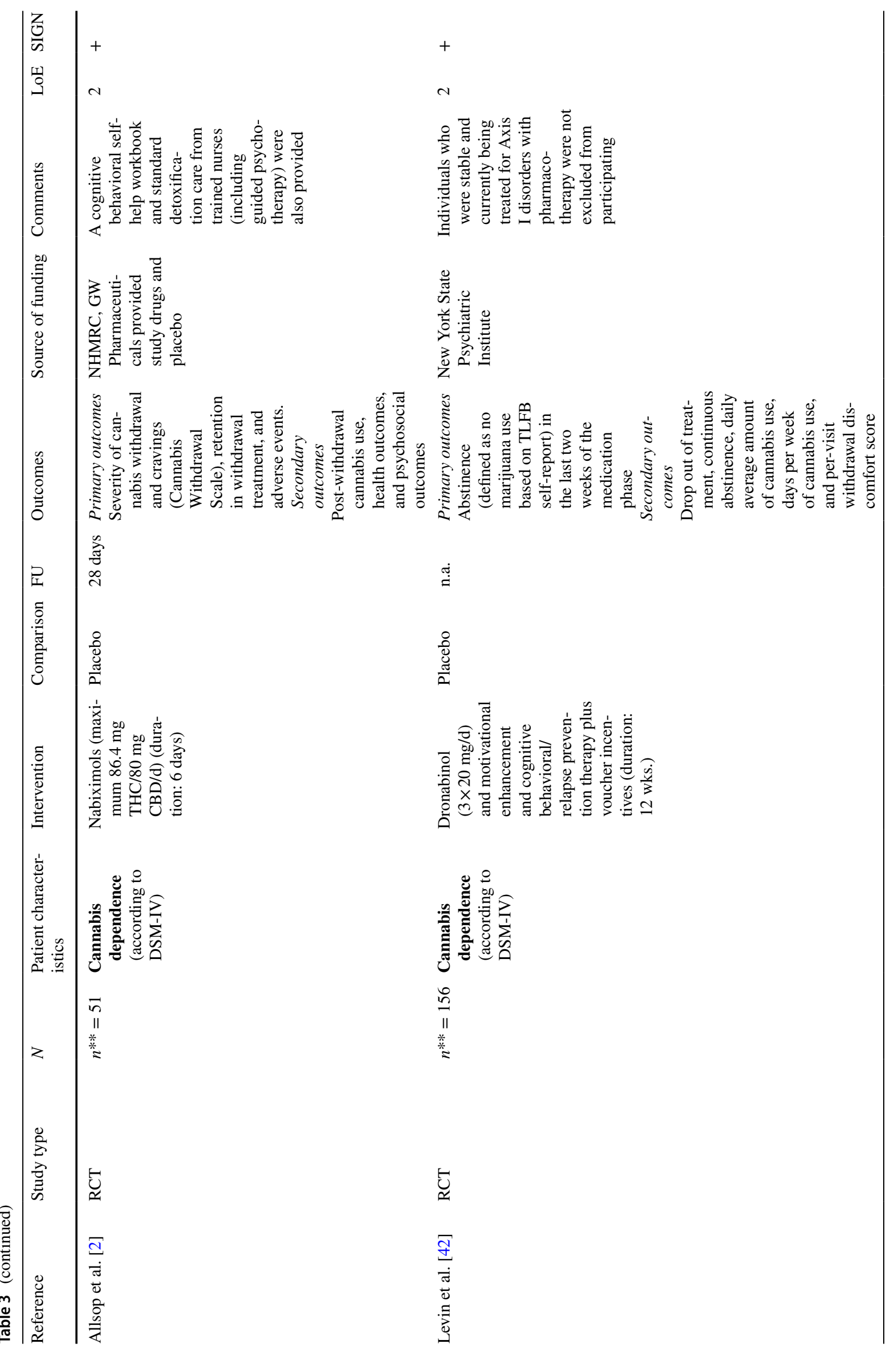




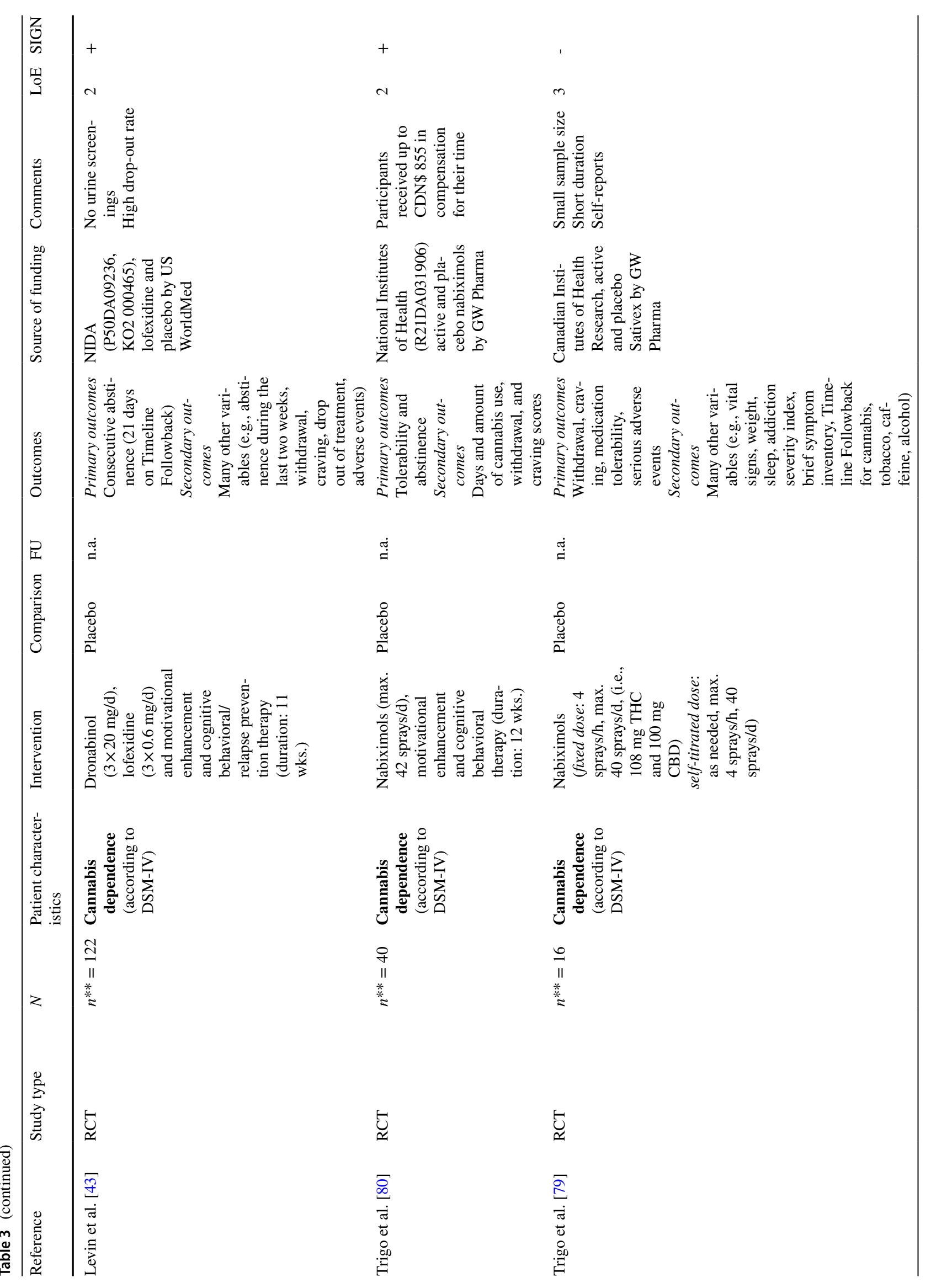




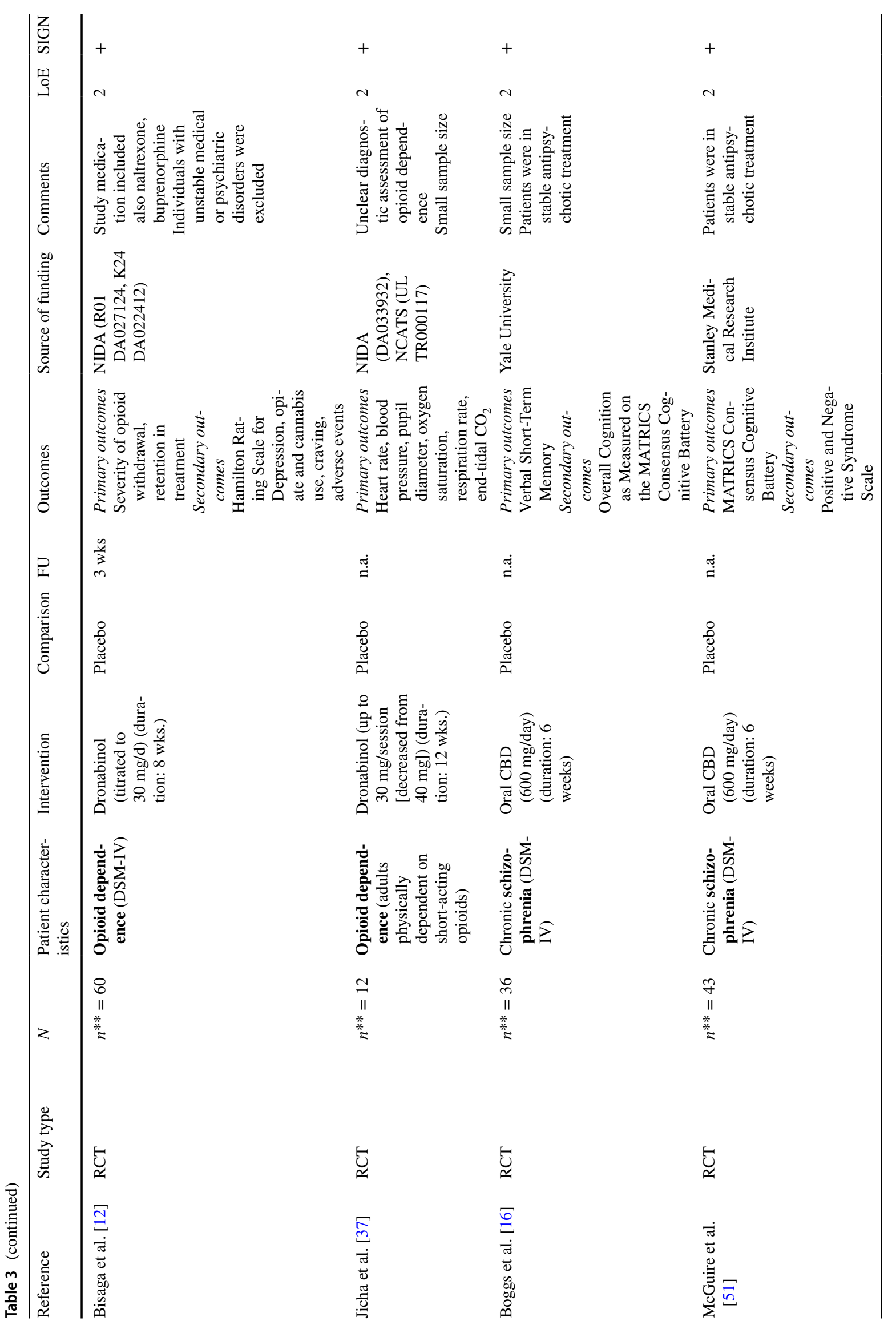




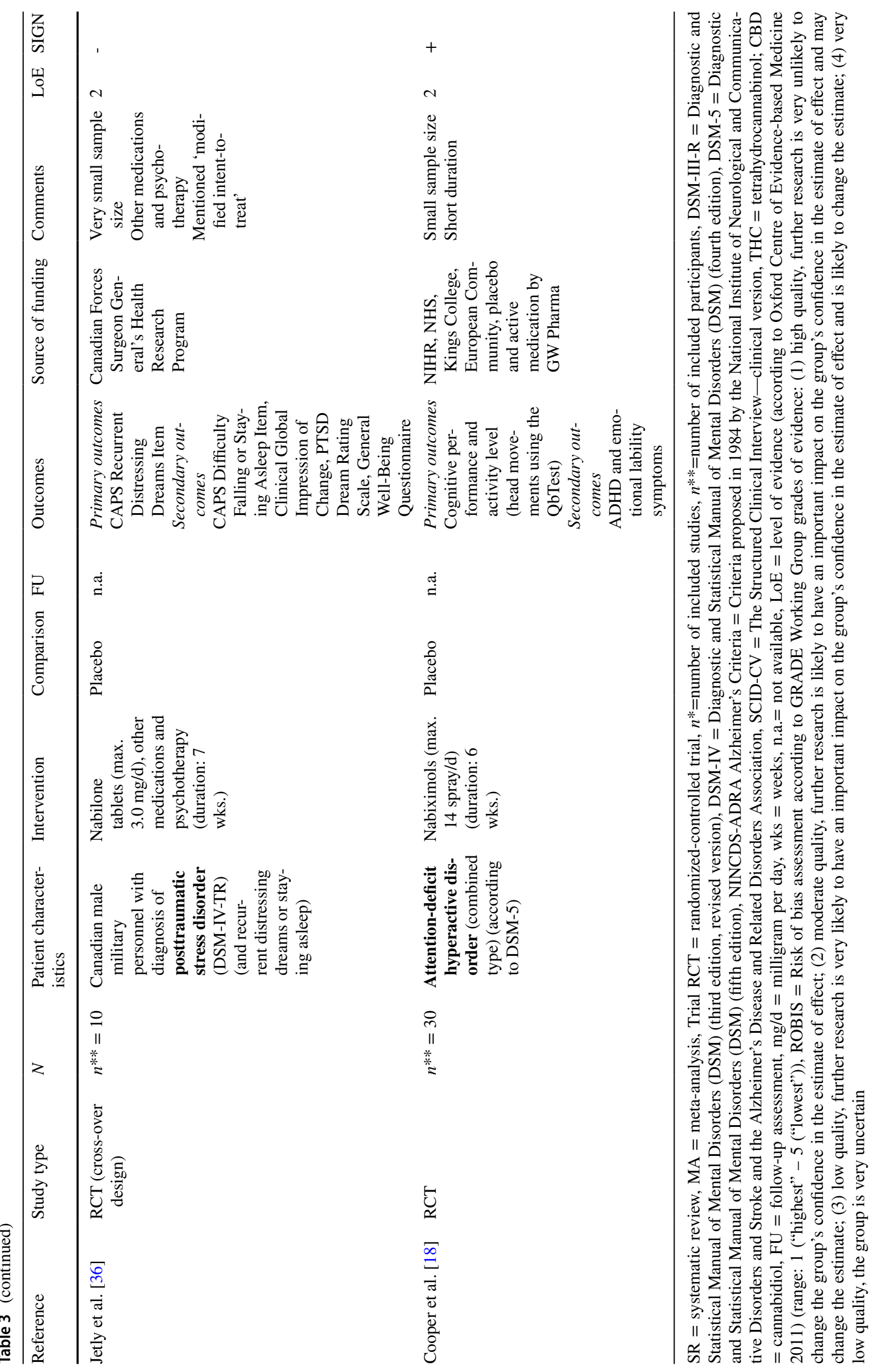


cases) were reported in the placebo lead-out phase. In a previous double-blind RCT, Levin et al. [42] tested dronabinol $(2 \times 20 \mathrm{mg} /$ day $)$ or placebo in addition to weekly motivational enhancement and relapse prevention therapy. There was no significant difference between treatment groups in the proportion of participants who achieved 2 weeks of abstinence at the end of the maintenance phase (dronabinol: $17.7 \%$; placebo: $15.6 \%$ ). Both groups reduced cannabis use over time (no differences between groups). Treatment retention was significantly higher at the end of the maintenance phase on dronabinol $(77 \%)$, compared to placebo $(61 \%)(p=0.02)$. Withdrawal symptoms were significantly lower on dronabinol than placebo $(p=0.02)$. Dronabinol was well-tolerated. Allsop et al. [2] assessed the effects of nabiximols or placebo combined with standardized psychosocial interventions. Nabiximols significantly reduced the overall severity of cannabis withdrawal relative to placebo ( $p=0.01)$, including effects on withdrawal-related irritability, depression, and cannabis cravings. Nabiximols patients remained longer in treatment during medication use (unadjusted hazard ratio, 3.66 [95\% CI, 1.18-11.37]; $p=0.02$ ), with a number needed to treat of 2.84 to achieve successful retention in treatment. The frequency $(p=0.59)$ and severity $(p=0.10)$ of adverse events did not differ significantly between groups. Both groups showed reduced cannabis use at follow-up, with no advantage of nabiximols over placebo for self-reported cannabis use $(p=0.75)$, cannabis-related problems $(p=0.14)$, or cannabis dependence $(p=0.89)$. In sum, existing trials provide a heterogeneous picture of the effectiveness of dronabinol and nabiximols in the treatment of cannabis use disorders. Four studies did not find positive effects regarding abstinence or reduction in cannabis use. Three out of five RCTs showed a significant reduction of withdrawal symptoms. Two out of three trials indicate improved craving and one study indicates improved retention in treatment. Adverse effects were more frequently reported in the intervention group in two of three studies. Future studies should use consistent outcome variables (e.g., assessment of abstinence) and treatments (manualized CBT/relapse prevention) in order to provide comparable findings.

Psychoses/Schizophrenia (F20 ICD-10) Two systematic reviews [45, 90] of 6 RCTs [13, 15, 46, 55, 74, 81] and two new RCTs $[16,51]$ were found ( $n=887$ participants). In the studies of Leweke and colleagues individuals with psychosis received CBD (800 mg/day, 4 weeks) [46] or CBD (600 mg/day, 2 weeks) [81]. The comparisons were amisulpride $(\max 800 \mathrm{mg} /$ day) and placebo, respectively. Primary outcomes were psychiatric symptoms [66] and positive and negative symptoms [39]. Both studies found significant improvements vs. baseline on days 14 and 28 for CBD and amisulpride; no difference was found between groups. The authors reported side effects for all medications, but the side-effect profile (extrapyramidal symptoms, weight gain, prolactin values) was considered superior for CBD vs. amisulpride [46]. McGuire et al. [51] conducted a double-blind parallel-group trial where patients with chronic schizophrenia received CBD (1000 $\mathrm{mg} / \mathrm{day} ; n=43)$ or placebo $(n=45)$ add-on to the existing antipsychotic medication. Participants were assessed before and after treatment using the Positive and Negative Syndrome Scale [39], the Global Assessment of Functioning scale (GAF) [40], Brief Assessment of Cognition in Schizophrenia (BACS) [41] and the improvement and severity scales of the clinical global impression scale [17] (CGI-I and CGI-S). After 6 weeks of treatment, compared to the placebo group, the CBD group had lower levels of positive symptoms (PANSS: treatment difference $=-1.4,95 \% \mathrm{CI}=-2.5,-0.2)$ and were more likely to have been rated as improved (CGI-I: treatment difference $=-0.5,95 \% \mathrm{CI}=-0.8,-0.1)$ and as not severely unwell (CGI-S: treatment difference $=-0.3$, $95 \% \mathrm{CI}=-0.5,0.0)$ by the treating clinician. Patients who received $\mathrm{CBD}$ also showed greater improvements which fell short of statistical significance in cognitive performance $(\mathrm{BACS}$ : treatment difference $=1.31,95 \%$ $\mathrm{CI}=-0.10,2.72)$ and in overall functioning (GAF: treatment difference $=3.0,95 \% \mathrm{CI}=-0.4,6.4)$. CBD was well tolerated, while rates of adverse events were similar between the CBD and placebo groups. Boggs et al. [16] conducted a 6-week parallel-group RCT. The intervention was a fixed-dose study of oral CBD (600 mg/day) or placebo augmentation in $n=36$ stable antipsychotic-treated patients diagnosed with chronic schizophrenia. This study compared the cognitive, symptomatic, and side effects of CBD vs. placebo in a clinical trial. No main effect of time or drug on MATRICS Consensus Cognitive Battery [10], but a significant drug $\times$ time effect was observed $(p=0.02)$. Post hoc analyses revealed that only placebotreated subjects improved over time $(p=0.03)$. There was a significant decrease in PANSS total scores over time $(p<0.0001)$, but there was no significant drug $\times$ time interaction $(p=0.18)$. Side effects were similar between CBD and placebo, with exception being sedation, which was more prevalent in the CBD group. Overall, CBD was well tolerated with no worsening of mood, suicidality or movement side effects. Leweke et al. [45] (LoE: 2; ROBIS: high) included 3 further published double-blind RCTs (of unclear risk of bias). The interventions were Rimonabant $[15,55]$ and drinabant (AVE1625) [74] compared to placebo $(n=3)$. The two CB1R antagonists/inverse agonists tested in schizophrenia had no significant effects on psychopathology and cognition. Rimonabant and drinabant (AVE1625) were withdrawn from worldwide marketing due to psychiatric side effects [45]. Altogether, cannabidiol plus existing antipsychotic medication showed beneficial effects. Improvements in psychotic symptoms and 
cognition were not superior to antipsychotic medication or placebo in 3 studies. More studies with larger sample sizes are needed to systematically investigate these effects.

Generalized social phobia (ICD 10 F40.11) One systematic review [90] including 1 RCT [11]. This RCT tested the effects of one experimental session of a simulated public speaking test on treatment-naive individuals with generalized social anxiety disorder $(n=36)$. Participants received either a single dose of CBD (600 mg; $n=12)$ or placebo $(n=12)$. Both groups were compared to healthy controls $(n=12)$. Subjective ratings on the Visual Analogue Mood Scale (VAM) [33, 88] and physiological measures (blood pressure, heart rate, skin conductance) were measured at six different time points during the tests. Medication with CBD significantly reduced anxiety, cognitive impairment and discomfort in their speech performance, and significantly decreased alert in their anticipatory speech. The placebo group presented higher anxiety, cognitive impairment, discomfort and alert levels when compared with the control group. No significant differences were observed between the CBD group and healthy controls in the negative selfstatement scores, cognitive impairment, discomfort, and alert factors. The increase in anxiety induced by the public speaking tests on subjects with generalized social anxiety disorders was reduced with the use of CBD, resulting in a similar response as the healthy controls. No adverse effects were found for CBD. More studies with larger sample sizes are needed to replicate the results of this study.

Posttraumatic stress disorder (ICD 10 F43.12) One RCT ( $\mathrm{n}=10$ participants) [36] assessed recurrent distressing nightmares in a sample of Canadian male military personnel with PTSD (DSM-IV). The intervention was nabilone $(0.5 \mathrm{mg}$, titrated to the effective dose (nightmare suppression) or reaching a maximum of $3.0 \mathrm{mg} / 7$ weeks). Subjects were allowed to continue psychotherapy and any other medication. The mean reduction in nightmares as measured by the CAPS Recurring and Distressing Dream scores [14] were $-3.6 \pm 2.4$ and $-1.0 \pm 2.1$ in the intervention and control group $(p=0.03)$. Mean global improvement as measured by the Clinical Global Impression of Change (CGI-C) [17] was $1.9 \pm 1.1$ (i.e., much improved) and $3.2 \pm 1.2$ (i.e., minimally improved) in the intervention and control group $(p=0.05)$. Five out of $10(50 \%)$ were much improved on nabilone vs. 1 out of $9(11 \%)$ on placebo. For the General Well-Being Questionnaire [71] improvements were $20.8 \pm 22$ and $-0.4 \pm 20.6$ in the nabilone and placebo groups, respectively $(p=0.04)$. No improvement of sleep intensity and quality was reported. Every second participant reported adverse events (nabilone group: 50\%; control group: $60 \%$ ). No event was severe nor resulted in a drop-out. More studies with larger sample sizes are needed to replicate these study results.
Anorexia nervosa (ICD 10 F50.0) One systematic review [28] of 1 RCT [5-7] was found. This study tested the effects of dronabinol $(2 \times 2.5 \mathrm{mg} /$ day; 4 weeks $)$ as add-on to standard psychotherapy and eating management in a sample of women with severe ( $>5$ years) anorexia nervosa (DSM-IV-TR) $(n=25)$. Primary outcomes were weight, behaviors and beliefs (Eating-Disorder Inventory II) [78] as well as physical activity. The trial found weight gain in both groups, with larger effects in the active treatment group $(1 \mathrm{~kg})$ vs placebo $(0.34 \mathrm{~kg})$. No changes were found in the Eating-Disorder Inventory and in the duration of physical activity. Adverse effects were reported in both groups (no serious adverse effects). More studies with larger sample sizes are needed to replicate these results.

Attention-deficit hyperactivity disorder (ADHD) (ICD 10 F90) The effects of Nabiximols compared to placebo were tested in one RCT ( $n=30$ adults) [18]. Patients currently treated with stimulants were asked to stop their medication for 1 week before their baseline assessments and for the duration of the study. Patients on long-acting medications, such as atomoxetine, were excluded from the study. The primary outcome was cognitive performance and activity level; secondary outcomes included ADHD and emotional lability symptoms. For the primary outcome, no significant difference was found (ITT-analysis) (Est $=-0.17,95 \% \mathrm{CI}-0.40$ to $0.07, p=0.16)$. For secondary outcomes, improvements in hyperactivity/impulsivity $(p=0.03)$ and a cognitive measure of inhibition ( $p=0.05)$ were found, but not in inattention $(p=0.10)$ or emotional lability $(p=0.11)$. Results did not meet significance following adjustment for multiple testing. One serious (muscular seizures/spasms) and three mild adverse events occurred in the active group and one serious adverse event (cardiovascular problems) in the placebo group. More studies with larger sample sizes are needed to replicate the results of this study.

Tourette's disorder (ICD 10 F95) One systematic review [90] identified 2 RCTs ( 3 reports, $n=36$ Patients) [60-62] in which therapy-resistant Tourette`s disorder $(n=12 / n=24)$ were assessed. The interventions were THC $(1 \times \max .10 \mathrm{mg})$ and THC (titrated to $10.0 \mathrm{mg} /$ day, 6 weeks), respectively. Comparisons were placebos (identical in taste and appearance). Multiple outcome variables were assessed (e.g., Tourette`s Syndrome Clinical Global Impressions Scale), Shapiro Tourette-Syndrome Severity Scale, Yale Global Tic Severity Scale (YGTSS) [87]. Both studies found improvement in various Tourette-related outcomes, of which not all reached statistical significance. Adverse effects were reported in both groups (no serious adverse effects). More studies with larger sample sizes are needed to replicate the results of these two studies. 


\section{Synthesis of results}

Due to a large heterogeneity of patient groups, interventions, comparisons and outcome criteria, data were not sufficient to calculate effect sizes and odds ratios.

\section{Discussion}

Only recently, cannabis-based medicine was tested more systematically for the treatment of mental disorders. The aim of this systematic review was to analyze its efficacy, tolerability and safety in patients with a diagnosed mental disorder. The literature research identified 4 SRs (of 11 RCTs) and 14 additional RCTs. A total of 1629 patients was examined, meeting criteria of 9 classified diagnoses of mental disorders (DSM-III-R, DSM-IV, DSM-5). Across studies, methodological limitations reduced the confidence in the evidence for several reasons: (1) for most indications, only single RCTs with small sample sizes (e.g., general social anxiety disorder, attention-deficit hyperactivity disorder) have been published. (2) In cases where more studies are available, results were mixed (e.g., dementia, cannabis use disorders) or did not consistently reach statistical significance (e.g., schizophrenia). A large variety of outcome variables were used and they were not comparable across studies.

The scientific literature shows, that among all cannabisbased medicines, THC-based preparations have been tested most frequently as treatment for mental disorders: Nabiximols (4 RCTs) [2, 18, 79, 80], dronabinol (6 RCTs) [5-7, $12,42,43,48,85]$, THC (5 RCTs) [1, 60-62, 82, 83], and nabilone [36]. All trials were placebo-controlled; other medication (e.g., benzodiazepines) and psychotherapy were available in most studies.

The largest number of controlled studies (7 RCTs) and thus best evidence available, is for THC-based medicine (nabiximols, dronabinol) as an adjunct to other interventions in the treatment of substance use disorders (cannabis dependence, opioid dependence). In cannabis dependent patients, a reduction of cannabis withdrawal symptoms was found in 3 RCTs [2, 42, 79], but not found in 2 studies $[43,80]$. Two out of three trials reported improved craving and one study indicates improved retention in treatment. Significant effects on abstinence or a reduction in substance use were not found between intervention and comparison groups. Adverse effects were more frequently reported in the intervention group in two of three studies. Future studies should use consistent outcome variables (e.g., assessment of abstinence) and treatments (manualized CBT/relapse prevention) to provide comparable findings. Among opioid dependent patients, a reduction in the severity of opioid withdrawal was reported in one study [12]. The evidence of THC-based preparations in the treatment of further mental disorders is also small, the effects are mixed. In Alzheimer`s disease results are inconsistent for the improvement of neuropsychiatric symptoms, mood and agitation in patients (3 RCTs) [82, 83, 85]. A consistent improvement of tics and behavioral problems was found in 2 studies including patients with therapy-resistant Tourette`s disorder. Not all results reached statistical significance [60-62]. For all other mental disorders, only single studies are available regarding the efficacy of THC-based medicine in these conditions. The reported therapeutic benefits in primary outcomes are: weight gain in patients with therapy-resistant anorexia nervosa (1 RCT) [5-7], improvement of nightmares and well-being in patients with posttraumatic stress disorder (1 RCT) [36]. In patients with attention-deficit hyperactivity disorder improvement in cognition and activity level did not reach statistical significance (1 RCT) [18]. Adverse events occurred in all studies, with no difference between groups. However, safety concerns appeared during opioid withdrawal for dronabinol at $20 \mathrm{mg}$ and higher [12].

Cannabidiol as a treatment of mental disorders was tested in 6 RCTs. Most data is available for patients with psychoses and schizophrenia. Cannabidiol (CBD) plus existing antipsychotic medication was associated with significantly lower levels of positive symptoms compared with the placebo group in 1 RCT [51]. Three further RCTs also found improvements in both psychotic symptoms and cognition, which fell short of statistical significance if compared to antipsychotic medication [46] or placebo [16, 81]. Positive anxiolytic effects of CBD were shown in patients with generalized social anxiety compared to a placebo group and healthy controls (1 RCT) [11]. No adverse effects have been reported for cannabidiol as treatment for mental disorders.

Other cannabis-based medicines were rimonabant and drinabant, which have been tested in 3 RCTs for the treatment of schizophrenia $[15,55,74]$. These studies found no benefits on cognition and psychiatric symptoms. Due to serious adverse effects, rimonabant and drinabant were withdrawn from the market.

In summary, the evidence for efficacy and safety of cannabis-based medicines as a treatment for mental disorders is still small. Reported improvements were mostly assessed in single RCTs with small sample sizes. In order to get a clearer picture of potential therapeutic effects, to reveal differential indications (which group of patients is most likely to benefit from cannabis preparations) and to allow a generalization towards naturalistic samples of patients, more clinical research of high methodological quality is needed. The required studies should be multi-centered, randomized and controlled, including large samples sizes. The currently existing trials generally tested cannabis-based medication for a few days up to several weeks. No follow-up assessments were conducted. Long-term data, however, are essential to get information on optimal treatment duration, sustained 
cannabinoid effects (e.g., tolerance, symptoms of withdrawal, cognition, quality of life, level of functioning) and safety. Consistent outcome measures (e.g., disorder remission, change in symptom severity, hospitalization, patient or care person's perception of improvement) should be used to assess the efficacy of cannabis medicine. Furthermore, to assess the potential of cannabis-based medicine in comparison to existing treatment options, future studies should have active control groups such as first-line pharmacological treatments (e.g., antidepressants, antipsychotic medication) and psychosocial treatments (e.g., manualized cognitive behavioral therapy) as comparisons.

\section{Conclusion}

THC- and CBD-based medicines were associated with improvements of several symptoms of mental disorders, but not with remission. Side effects can occur, but severe AEs were mentioned in single cases only. The overall confidence in the evidence is low. To provide reliable treatment recommendations, more high-quality RCTs with larger sample sizes are requested.

Acknowledgements We acknowledge the contribution of Johannes Kabisch, Kathrin Schacherbauer, Sophia Schmieder, Luise Jacob, Christina Adorjan, Udo Bonnet, Jan Copeland, Peter Falkai, Marica Ferri, Christopher Fowler, Winfried Häuser, Derik Hermann, Burkhard Hinz, Michael Höfler, Joseph Kambeitz, Dagmar Koethe, Ludwig Kraus, Markus Leweke, Beat Lutz, Liane Paul, Nina Sarubin, Frank Petzke, Tim Pfeiffer-Gerschel, Lukas Radbruch, Roland Simon, Michael Schäfer and Martin Storr.

Funding This work was prepared in the context of the study "Cannabis: Potential and risks. A scientific analysis (CaPRis)" (PI: Dr. Eva Hoch, Dr. Miriam Schneider) [31] funded by the German Ministry of Health. The funding sources had no influence on the design of the study or the analysis and interpretation of the results.

\section{Compliance with ethical standards}

Conflict of interest The authors have no conflict of interest.

Open Access This article is distributed under the terms of the Creative Commons Attribution 4.0 International License (http://creativecommons.org/licenses/by/4.0/), which permits unrestricted use, distribution, and reproduction in any medium, provided you give appropriate credit to the original author(s) and the source, provide a link to the Creative Commons license, and indicate if changes were made.

\section{References}

1. Ahmed AI, van den Elsen GA, Colbers A, Kramers C, Burger DM, van der Marck MA, Olde Rikkert MG (2015) Safety, pharmacodynamics, and pharmacokinetics of multiple oral doses of delta-9-tetrahydrocannabinol in older persons with dementia. Psychopharmacology 232:2587-2595

2. Allsop DJ, Copeland J, Lintzeris N, Dunlop AJ, Montebello M, Sadler C, Rivas GR, Holland RM, Muhleisen P, Norberg MM, Booth J, McGregor IS (2014) Nabiximols as an agonist replacement therapy during cannabis withdrawal: a randomized clinical trial. JAMA Psychiatry 71:281-291

3. American Psychiatric Association (2000) Diagnostic and statistical manual of mental disorders (4th edn). American Psychiatric Association: Washington, DC

4. American Psychiatric Association (2013) Diagnostic and statistical manual of mental disorders: DSM-5. American Psychiatric Association: Arlington, VA

5. Andries A, Frystyk J, Flyvbjerg A, Stoving RK (2015) Changes in IGF-I, urinary free cortisol and adipokines during dronabinol therapy in anorexia nervosa: results from a randomised, controlled trial. Growth Horm IGF Res 25:247-252

6. Andries A, Frystyk J, Flyvbjerg A, Støving RK (2014) Dronabinol in severe, enduring anorexia nervosa: a randomized controlled trial. Int J Eat Disord 47:18-23

7. Andries A, Gram B, Stoving RK (2015) Effect of dronabinol therapy on physical activity in anorexia nervosa: a randomised, controlled trial. Eat Weight Disord 20:13-21

8. Ashton CH (2018) Pharmacology and effects of cannabis: a brief review. Br J Psychiatry 178:101-106

9. Atakan Z (2012) Cannabis, a complex plant: different compounds and different effects on individuals. Therap Adv Psychopharmacol 2:241-254

10. August SM, Kiwanuka JN, McMahon RP, Gold JM (2012) The MATRICS consensus cognitive battery (MCCB): clinical and cognitive correlates. Schizophrenia Res 134:76-82

11. Bergamaschi MM, Queiroz RH, Chagas MH, de Oliveira DC, De Martinis BS, Kapczinski F, Quevedo J, Roesler R, Schroder N, Nardi AE, Martin-Santos R, Hallak JE, Zuardi AW, Crippa JA (2011) Cannabidiol reduces the anxiety induced by simulated public speaking in treatment-naive social phobia patients. Neuropsychopharmacology 36:1219-1226

12. Bisaga A, Sullivan MA, Glass A, Mishlen K, Pavlicova M, Haney M, Raby WN, Levin FR, Carpenter KM, Mariani JJ, Nunes EV (2015) The effects of dronabinol during detoxification and the initiation of treatment with extended release naltrexone. Drug Alcohol Depend 154:38-45

13. Bisogno T, MacCarrone M, De Petrocellis L, Jarrahian A, FinazziAgro A, Hillard C, Di Marzo V (2001): The uptake by cells of 2- arachidonoylglycerol, an endogenous agonist of cannabinoid receptors.Eur J Biochem 268:1982-1989

14. Blake DD, Weathers FW, Nagy LM, Kaloupek DG, Gusman FD, Charney DS, Keane TM (1995) The development of a clinicianadministered PTSD Scale. J Trauma Stress 8:75-90

15. Boggs DL, Kelly DL, McMahon RP, Gold JM, Gorelick DA, Linthicum J, Conley RR, Liu F, Waltz J, Huestis MA, Buchanan RW (2012) Rimonabant for neurocognition in schizophrenia: a 16-week double blind randomized placebo controlled trial. Schizophr Res 134:207-210

16. Boggs DL, Surti T, Gupta A, Gupta S, Niciu M, Pittman B, Martin AMS, Thurnauer H, Davies A, D'Souza DC, Ranganathan M (2018) The effects of cannabidiol (CBD) on cognition and symptoms in outpatients with chronic schizophrenia a randomized placebo controlled trial. Psychopharmacology 235:1923-1932

17. Busner J, Targum SD (2007) The clinical global impressions scale: applying a research tool in clinical practice. Psychiatry (Edgmont) 4:28-37

18. Cooper RE, Williams E, Seegobin S, Tye C, Kuntsi J, Asherson P (2017) Cannabinoids in attention-deficit/hyperactivity 
disorder: a randomised-controlled trial. Eur Neuropsychopharmacol 27:795-808

19. Crowe A, Lyness KP (2013) Family functioning, coping, and distress in families with serious mental illness. Fam J 22:186-197

20. Di Marzo V, Melck D, Bisogno T, De Petrocellis L (1998) Endocannabinoids: endogenous cannabinoid receptor ligands with neuromodulatory action. Trends Neurosci 21:521-528

21. Di Marzo V, Petrosino S (2007) Endocannabinoids and the regulation of their levels in health and disease. Curr Opin Lipidol 18:129-140

22. Fattore L (2015) Preface. In: Fattore L (ed) Cannabinoids in neurologic and mental disease, Academic Press, San Diego, $\mathrm{p}$ xvii

23. Fowler CJ, Rojo ML, Rodriguez-Gaztelumendi A (2010) Modulation of the endocannabinoid system: Neuroprotection or neurotoxicity? Exp Neurol 224:37-47

24. Gaetani S, Dipasquale P, Romano A, Righetti L, Cassano T, Piomelli D, Cuomo V (2009) The endocannabinoid system as a target for novel anxiolytic and antidepressant drugs. Int Rev Neurobiol 85:57-72

25. GBD 2016 DALYs and HALE Collaborators (2017) Global, regional, and national disability-adjusted life-years (DALYs) for 333 diseases and injuries and healthy life expectancy (HALE) for 195 countries and territories, 1990-2016: a systematic analysis for the Global Burden of Disease Study 2016. Lancet 390:1260-1344

26. Grotenhermen F, Muller-Vahl K (2012) The therapeutic potential of cannabis and cannabinoids. Deutsches Arzteblatt Int 109:495-501

27. Hall W, Renström M, Poznyak V (2016) The health and social effects of nonmedical cannabis use. World Health Organization, Geneva

28. Hay P, Touyz S (2015) Treatment of patients with severe and enduring eating disorders. Curr Opin Psychiatry 28:473-477

29. Higgins JPT, Green S (2011) Cochrane handbook for systematic reviews of interventions version 5.1.0 [updated March 2011]. The Cochrane Collaboration, London

30. Hill MN, Tasker JG (2012) Endocannabinoid signaling, glucocorticoid-mediated negative feedback and regulation of the HPA axis. Neuroscience 204:5-16

31. Hoch E, Friemel C, Schneider M (2018) Cannabis: Potenzial und Risiko [Cannabis: Potential and Risks]. Springer, Heidelberg

32. Hoch E, Bonnet U, Thomasius R, Ganzer F, Havemann-Reinecke U, Preuss UW (2015) Risks associated with the non-medicinal use of cannabis. Deutsches Ärzteblatt International 112:271-278

33. Hofmann SG, DiBartolo PM (2000) An instrument to assess self-statements during public speaking: scale development and preliminary psychometric properties. Behav Therap 31:499-515

34. Huestis MA (2007) Human cannabinoid pharmacokinetics. Chem Biodivers 4:1770-1804

35. Ibarra-Lecue I, Pilar-Cuellar F, Muguruza C, Florensa-Zanuy E, Diaz A, Uriguen L, Castro E, Pazos A, Callado LF (2018) The endocannabinoid system in mental disorders: evidence from human brain studies. Biochem Pharmacol

36. Jetly R, Heber A, Fraser G, Boisvert D (2015) The efficacy of nabilone, a synthetic cannabinoid, in the treatment of PTSDassociated nightmares: a preliminary randomized, double-blind, placebo-controlled cross-over design study. Psychoneuroendocrinology 51:585-588

37. Jicha CJ, Lofwall MR, Nuzzo PA, Babalonis S, Elayi SC, Walsh SL (2015) Safety of oral dronabinol during opioid withdrawal in humans. Drug Alcohol Depend 157:179-183

38. Karanian DA, Bahr BA (2006) Cannabinoid drugs and enhancement of endocannabinoid responses: strategies for a wide array of disease states. Curr Mol Med 6:677-684
39. Kay SR, Fiszbein A, Opler LA (1987) The positive and negative syndrome scale (PANSS) for schizophrenia. Schizophr Bull 13:261-276

40. Keefe RS, Goldberg TE, Harvey PD, Gold JM, Poe MP, Coughenour L (2004) The brief assessment of cognition in schizophrenia: reliability, sensitivity, and comparison with a standard neurocognitive battery. Schizophr Res 68:283-297

41. Keefe RS, Poe M, Walker TM, Harvey PD (2006) The relationship of the Brief Assessment of Cognition in Schizophrenia (BACS) to functional capacity and real-world functional outcome. J Clin Exp Neuropsychol 28:260-269

42. Levin FR, Mariani JJ, Brooks DJ, Pavlicova M, Cheng W, Nunes EV (2011) Dronabinol for the treatment of cannabis dependence: a randomized, double-blind, placebo-controlled trial. Drug Alcohol Depend 116:142-150

43. Levin FR, Mariani JJ, Pavlicova M, Brooks D, Glass A, Mahony A, Nunes EV, Bisaga A, Dakwar E, Carpenter KM, Sullivan MA, Choi JC (2016) Dronabinol and lofexidine for cannabis use disorder: a randomized, double-blind, placebo-controlled trial. Drug Alcohol Depend 159:53-60

44. Leweke FM, Koethe D (2008) Cannabis and psychiatric disorders: it is not only addiction. Addict Biol 13:264-275

45. Leweke FM, Mueller JK, Lange B, Rohleder C (2016) Therapeutic potential of cannabinoids in psychosis. Biol Psychiatry 79:604-612

46. Leweke FM, Piomelli D, Pahlisch F, Muhl D, Gerth CW, Hoyer C, Klosterkotter J, Hellmich M, Koethe D (2012) Cannabidiol enhances anandamide signaling and alleviates psychotic symptoms of schizophrenia. Transl Psychiatry 2:e94

47. Lewin S, Glenton C, Munthe-Kaas H, Carlsen B, Colvin CJ, Gulmezoglu M, Noyes J, Booth A, Garside R, Rashidian A (2015) Using qualitative evidence in decision making for health and social interventions: an approach to assess confidence in findings from qualitative evidence syntheses (GRADE-CERQual). PLoS Med 12:e1001895

48. Lofwall MR, Babalonis S, Nuzzo PA, Elayi SC, Walsh SL (2016) Opioid withdrawal suppression efficacy of oral dronabinol in opioid dependent humans. Drug Alcohol Depend 164:143-150

49. Lu H-C, Mackie K (2016) An Introduction to the Endogenous Cannabinoid System. Biol Psychiatry 79:516-525

50. Maroon J, Bost J (2018) Review of the neurological benefits of phytocannabinoids. Surg Neurol Int 9:91

51. McGuire P, Robson P, Cubala WJ, Vasile D, Morrison PD, Barron R, Taylor A, Wright S (2018) Cannabidiol (CBD) as an adjunctive therapy in schizophrenia: a multicenter randomized controlled trial. Am J Psychiatry 175:225-231

52. Mechoulam R, Hanus L (2000) A historical overview of chemical research on cannabinoids. Chem Phys Lipids 108:1-13

53. Mechoulam R, Parker LA (2013) The endocannabinoid system and the brain. Annu Rev Psychol 64:21-47

54. Mechoulam R, Peters M, Murillo-Rodriguez E, Hanus LO (2007) Cannabidiol-recent advances. Chem Biodivers 4:1678-1692

55. Meltzer HY, Arvanitis L, Bauer D, Rein W (2004) Placebocontrolled evaluation of four novel compounds for the treatment of schizophrenia and schizoaffective disorder. Am J Psychiatry 161:975-984

56. Moher D, Liberati A, Tetzlaff J, Altman DG, The PG (2009) Preferred reporting items for systematic reviews and meta-analyses: the PRISMA statement. PLoS Med 6:e1000097

57. Morales P, Hurst DP, Reggio PH (2017) Molecular targets of the phytocannabinoids-a complex picture. Progress Chem Org Nat Product 103:103-131

58. Moreira FA, Lutz B (2008) The endocannabinoid system: emotion, learning and addiction. Addict Biol 13:196-212 
59. Mucke M, Carter C, Cuhls H, Pruss M, Radbruch L, Hauser W (2016) Cannabinoids in palliative care: systematic review and meta-analysis of efficacy, tolerability and safety. [German] Schmerz 30:25-36

60. Muller-Vahl KR, Koblenz A, Jobges M, Kolbe H, Emrich HM, Schneider U (2001) Influence of treatment of Tourette syndrome with delta9-tetrahydrocannabinol (delta9-THC) on neuropsychological performance. Pharmacopsychiatry 34:19-24

61. Muller-Vahl KR, Schneider U, Koblenz A, Jobges M, Kolbe H, Daldrup T, Emrich HM (2002) Treatment of Tourette's syndrome with Delta 9-tetrahydrocannabinol (THC): a randomized crossover trial. Pharmacopsychiatry 35:57-61

62. Muller-Vahl KR, Schneider U, Prevedel H, Theloe K, Kolbe H, Daldrup T, Emrich HM (2003) Delta 9-tetrahydrocannabinol (THC) is effective in the treatment of tics in Tourette syndrome: a 6-week randomized trial. J Clin Psychiatry 64:459-465

63. National Academies of Sciences and Medicine (2017) The health effects of cannabis and cannabinoids: current state of evidence and recommendations for research. The National Academies Press, Washington

64. National Research C, Institute of Medicine Committee on the Prevention of Mental D, Substance Abuse Among Children Y, Young Adults: Research A, Promising I (2009) The National Academies Collection: Reports funded by National Institutes of Health. In: O'Connell ME, Boat T, Warner KE (eds) Preventing mental, emotional, and behavioral disorders among young people: progress and possibilities. National Academies Press (US)

65. OCEBM (2011) Levels of evidence working group. The oxford levels of evidence, 2 edn. Oxford Centre for Evidence-Based Medicine, Oxford. http://www.cebm.net/index.aspx?o=5653

66. Overall JE, Gorham DR (1962) The brief psychiatric rating scale. Psychol Rep 10:799-812

67. Parolaro D, Realini N, Vigano D, Guidali C, Rubino T (2010) The endocannabinoid system and psychiatric disorders. Exp Neurol 224:3-14

68. Parsons LH, Hurd YL (2015) Endocannabinoid signalling in reward and addiction. Nat Rev Neurosci 16:579-594

69. Pertwee RG (2008) The diverse CB1 and CB2 receptor pharmacology of three plant cannabinoids: delta9-tetrahydrocannabinol, cannabidiol and delta9-tetrahydrocannabivarin. Br J Pharmacol 153:199-215

70. Pertwee RG (2009) Emerging strategies for exploiting cannabinoid receptor agonists as medicines. Br J Pharmacol 156:397-411

71. Pouwer F, van der Ploeg HM, Ader HJ, Heine RJ, Snoek FJ (1999) The 12-item well-being questionnaire. An evaluation of its validity and reliability in Dutch people with diabetes. Diabetes Care 22:2004-2010

72. RodrÍGuez de Fonseca, F, Del Arco I, Bermudez-Silva FJ, Bilbao A, Cippitelli A, Navarro M (2005) The endocannabinoid system: physiology and pharmacology. Alcohol Alcohol 40:2-14

73. Rubino T, Zamberletti E, Parolaro D (2015) Endocannabinoids and mental disorders. Handb Exp Pharmacol 231:261-283

74. Sanofi (2009) Efficacy and safety of AVE1625 as a co-treatment with antipsychotic therapy in schizophrenia (CONNECT)

75. Scarante FF, Vila-Verde C, Detoni VL, Ferreira-Junior NC, Guimaraes FS, Campos AC (2017) Cannabinoid modulation of the stressed hippocampus. Front Mol Neurosci 10:411

76. SIGN (2015) Scottisch intercollegiate guidelines network 50 methodology checklist. Edinburgh, United Kingdom

77. Steel Z, Marnane C, Iranpour C, Chey T, Jackson JW, Patel V, Silove D (2014) The global prevalence of common mental disorders: a systematic review and meta-analysis 1980-2013. Int J Epidemiol 43:476-493
78. Thiel A, Paul T (2006) Test-retest reliability of the eating disorder inventory 2. J Psychosomat Res 61:567-569

79. Trigo JM, Lagzdins D, Rehm J, Selby P, Gamaleddin I, Fischer B, Barnes AJ, Huestis MA, Le Foll B (2016) Effects of fixed or selftitrated dosages of Sativex on cannabis withdrawal and cravings. Drug Alcohol Depend 161:298-306

80. Trigo JM, Soliman A, Quilty LC, Fischer B, Rehm J, Selby P, Barnes AJ, Huestis MA, George TP, Streiner DL, Staios G, Le Foll B (2018) Nabiximols combined with motivational enhancement/cognitive behavioral therapy for the treatment of cannabis dependence: A pilot randomized clinical trial. PLoS One 13:e0190768

81. University of Cologne (2008) A clinical trial on the antipsychotic properties of cannabidiol. https://clinicaltrials.gov/ct2/show/ NCT00309413? cond=Cannabidiol\%26rank=67. Accessed 21 Jan 2015

82. van den Elsen GA, Ahmed AI, Verkes RJ, Feuth T, van der Marck MA, Olde Rikkert MG (2015) Tetrahydrocannabinol in behavioral disturbances in dementia: a crossover randomized controlled trial. Am J Geriatric Psychiatry 23:1214-1224

83. van den Elsen GAH, Ahmed AIA, Jan Verkes R, Kramers K, Feuth T, Olde Rikkert MGM, Van Der Marck MA (2015) Efficacy and safety of delta-9-tetrahydrocannabinol in behavioral disturbances in dementia: a randomized controlled trial. Alzheimer's Dement 1:P469-P470

84. van den Elsen GAH, Ahmed AIA, Verkes R-J, Kramers C, Feuth T, Rosenberg PB, van der Marck MA, Olde Rikkert MGM (2015) Tetrahydrocannabinol for neuropsychiatric symptoms in dementia: a randomized controlled trial. Neurology 84:2338-2346

85. Volicer L, Stelly M, Morris J, McLaughlin J, Volicer BJ (1997) Effects of dronabinol on anorexia and disturbed behavior in patients with Alzheimer's disease. Int J Geriatric Psychiatry 12:913-919

86. Volkow ND, Baler RD, Compton WM, Weiss SR (2014) Adverse health effects of marijuana use. N Engl J Med 370:2219-2227

87. Walkup JT, Rosenberg LA, Brown J, Singer HS (1992) The validity of instruments measuring tic severity in Tourette's syndrome. J Am Acad Child Adolescent Psychiatry 31:472-477

88. Wewers ME, Lowe NK (1990) A critical review of visual analogue scales in the measurement of clinical phenomena. Res Nurs Health $13: 227-236$

89. Whiteford HA, Ferrari AJ, Degenhardt L, Feigin V, Vos T (2015) The global burden of mental, neurological and substance use disorders: an analysis from the Global Burden of Disease Study 2010. PLoS One 10:e116820

90. Whiting PF, Wolff RF, Deshpande S, Di Nisio M, Duffy S, Hernandez AV, Keurentjes JC, Lang S, Misso K, Ryder S, Schmidlkofer S, Westwood M, Kleijnen J (2015) Cannabinoids for medical use: A systematic review and meta-analysis. JAMA 313:2456-2473

91. Wittchen HU, Jacobi F, Rehm J, Gustavsson A, Svensson M, Jonsson B, Olesen J, Allgulander C, Alonso J, Faravelli C, Fratiglioni L, Jennum P, Lieb R, Maercker A, van Os J, Preisig M, SalvadorCarulla L, Simon R, Steinhausen HC (2011) The size and burden of mental disorders and other disorders of the brain in Europe 2010. Eur Neuropsychopharmacol 21:655-679

92. World Drug Report (2018) United Nations Publication, Sales No. E.18.XI.9

93. World Health Organization (2004) ICD-10: international statistical classification of diseases and related health problems/World Health Organization. World Health Organization, Geneva 